\title{
Kcne4 Deletion Sex-Dependently Alters Vascular Reactivity
}

\author{
Geoffrey W. Abbott ${ }^{\mathrm{a}}$ Thomas A. Jepps ${ }^{\mathrm{b}}$ \\ ${ }^{a}$ Bioelectricity Laboratory, Departments of Pharmacology and Physiology and Biophysics, School of Medicine, \\ University of California, Irvine, Calif., USA; ${ }^{b}$ Ion Channels Group, Department of Biomedical Sciences, University of \\ Copenhagen, Copenhagen, Denmark
}

\section{Key Words}

Kv7 channels $\cdot$ KCNE subunits $\cdot \mathrm{KCNE} 4 \cdot \mathrm{KCNQ} \cdot$ Potassium channels · Vascular physiology $\cdot$ Smooth muscle

\begin{abstract}
Voltage-gated potassium (Kv) channels formed by Kv7 (KCNQ) a-subunits are recognized as crucial for vascular smooth muscle function, in addition to their established roles in the heart (Kv7.1) and the brain (Kv7.2-5). In vivo, Kv7 a-subunits are often regulated by KCNE subfamily ancillary ( $\beta$ ) subunits. We investigated the effects of targeted germline Kcne4 deletion on mesenteric artery reactivity in adult male and female mice. Kcne4 deletion increased mesenteric artery contractility in response to a-adrenoceptor agonist methoxamine, and decreased responses to Kv7.2-7.5 channel activator ML213, in male but not female mice. In contrast, Kcne4 deletion markedly decreased vasorelaxation in response to isoprenaline in both male and female mice. Kcne4 expression was 2 -fold lower in the female versus the male mouse mesenteric artery, and Kcne4 deletion elicited only moderate changes of other Kcne transcripts, with no striking sex-specific differences. However, Kv7.4 protein expression in females was twice that in males, and was reduced in both sexes by Kcne4 deletion. Our findings confirm a crucial role for KCNE4 in regulation of Kv7 channel activity to modulate
\end{abstract}

\section{KARGER}

(C) 2016 S. Karger AG, Base

$1018-1172 / 16 / 0534-0138 \$ 39.50 / 0$

E-Mail karger@karger.com

www.karger.com/jvr vascular tone, and provide the first known molecular mechanism for sex-specificity of this modulation that has important implications for vascular reactivity and may underlie sex-specific susceptibility to cardiovascular diseases.

(c) 2016 S. Karger AG, Basel

\section{Introduction}

KCNE4 is a member of the KCNE family (KCNE1-5) of single transmembrane-spanning $\beta$-subunits. Although these proteins do not form functional channels by themselves, they coassemble with pore-forming a-subunits of voltage-gated potassium $(\mathrm{Kv})$ channels to regulate the trafficking, biophysical properties and pharmacology of the resultant heteromeric channel complexes [1]. The KCNE $\beta$-subunits can dramatically affect the activity of different ion channels; however, our understanding of their functional impact in many native systems is still limited. Recently, we showed that KCNE4 (also known as MiRP3) plays a fundamental role in regulating vascular tone [2]. In mesenteric artery myocytes from adult male

Dr. Geoffrey W. Abbott

A-360 Medical Surge II, Department of Pharmacology, School of Medicine

University of California, Irvine

Irvine, CA 92697-4625 (USA)

E-Mail abbottg@uci.edu

Dr. Thomas A. Jepps

Department of Biomedical Sciences, University of Copenhagen

The Panum Institute, Blegdamsvej 3

DK-2200 Copenhagen N (Denmark)

E-Mail tjepps@sund.ku.dk 
rats, KCNE4 coassembled with the Kv7.4 and Kv7.5 a-subunits (encoded by KCNQ4 and KCNQ5, respectively), and knockdown of KCNE4 coincided with reduced Kv7.4 membrane expression and a more depolarized membrane potential [2].

$\mathrm{Kv} 7.4$ is a member of the Kv7 subfamily of $\mathrm{Kv}$ channel a-subunits, and has been widely reported to regulate vascular (and nonvascular) smooth muscle resting membrane potential [3-5]. The Kv7 family is comprised of 5 members (Kv7.1-5), of which Kv7.1, Kv7.4, and Kv7.5 are expressed in different rodent and human arteries $[3,5,6]$. In vascular smooth muscle, Kv7.4 and Kv7.5 channels predominate functionally, and recent evidence suggests that these isoforms coassemble to form heteromultimeric channels $[2,7,8]$. Pharmacological blockade of Kv7 channels produces vasoconstriction in several rodent and human blood vessels, and activation of Kv7 channels mediates relaxation in precontracted vessels $[5,6,8-$ 10]. Moreover, Kv7 channel blockade, or Kv7.4 channel knockdown, impairs various receptor-mediated vasorelaxations in different arteries. Thus, the vascular Kv7 channels are regarded as functional mediators of different receptor-activated vasodilatations [7, 11-15].

To date, these studies have used mainly male animal models, even though there are many sex-dependent differences in vascular physiology $[16,17]$. Susceptibility to certain vascular diseases also differs between genders. Vascular diseases, such as hypertension, are typically more common in males and postmenopausal women than in premenopausal women [18-21]. Sex-dependent differences have been associated with different circulating androgen levels; however, we still do not understand the molecular mechanisms responsible for these differences in the vasculature $[17,18,22]$.

Recently, using a germline Kcne4-deleted (Kcne $4^{-1-}$ ) mouse line, we showed cardiac KCNE4 expression to be positively regulated by $5 \alpha$-dihydrotestosterone (DHT), which corresponded with male mice displaying higher ventricular myocyte $\mathrm{Kv}$ current densities than female mice [23]. Ventricular Kv current density in young, sexually mature female mice was unaffected by Kcne 4 deletion and was similar to that of male Kcne $4^{-/-}$mice. This difference was associated with KCNE4 upregulating Kv1.5 and Kv4.2 currents specifically in male $\mathrm{Kcne}^{+/+}$mice due to Kcne4 expression upregulation by DHT.

Given the newly identified role for KCNE4 in the vasculature, here we investigated the effects of Kcne4 deletion on vascular function in mice, and found that Kcne4 sex-specifically regulates mouse vascular reactivity.

\section{Methods}

\section{Animals}

The $\mathrm{Kcne}^{-1-}$ mouse line was generated by replacement of the sole coding exon of Kcne4 with the neo and LacZ genes in 129/Sv embryonic stem cells for embryonic injection followed by implantation into a C57 breeder. Progeny were genotyped by PCR and for final confirmation, Southern blot (performed by Lexicon, The Woodlands, Tex. and Texas A\&M Institute for Genomic Medicine, College Station, Tex., USA; data not shown) [23]. Heterozygotes $\left(\mathrm{Kcne}^{+/-}\right)$were then backcrossed for at least 10 generations into the $\mathrm{C} 57 \mathrm{BL} / 6$ strain. We genotyped the colony by conventional PCR of genomic DNA isolated from tail tips, using primers of the following sequences: Kcne4 forward 5'-CAACGACAGCAGTGAAGGC-3', Kcne4 reverse 5'-GCAGAGCAAAAGCAAAACCC-3', Neo3a 5'-GCAGCGCATCGCCTTCTATC [23]. Mice were housed in a pathogen-free facility; colony maintenance, genotyping, euthanasia and tissue isolations were approved by the Animal Care and Use Committees, University of California, Irvine, and were conducted in strict accordance with recommendations in the Guide for the Care and Use of Laboratory Animals of the National Institutes of Health.

\section{Myography}

Studies were performed on 6- to 8-month-old sexually mature male and female mice, after euthanasia by $\mathrm{CO}_{2}$ asphyxiation. The intestines were immediately removed, placed in ice-cold physiological saline solution (PSS) and the 2nd- and 3rd-order mesenteric arteries were dissected. The arteries were cleaned of adherent tissue and segments (approx. $2 \mathrm{~mm}$ ) were mounted on $40-\mu \mathrm{m}$ stainless-steel wire in a myograph (Danish Myo Technology) for isometric tension recording. The myograph chambers were filled with PSS, maintained at $37^{\circ} \mathrm{C}$ and aerated with $95 \% \mathrm{O}_{2} / 5 \% \mathrm{CO}_{2}$. The vessels were allowed to equilibrate at $37^{\circ} \mathrm{C}$ before undergoing a passive-force normalization procedure.

Increasing concentrations $(0.1-30 \mu \mathrm{M})$ of the $\alpha$-adrenoceptor agonist, methoxamine (Sigma), were applied. The vessels were then washed in fresh PSS before they were precontracted with 10 $\mu \mathrm{M}$ methoxamine, and then increasing concentrations of the Kv7.2-7.5 channel activator, ML213 (0.1-10 $\mu \mathrm{M}$; Tocris), or the $\beta$-adrenoceptor agonist, isoprenaline (0.1-3 $\mu \mathrm{M}$; Sigma), were applied. The isoprenaline concentration response curve was then repeated in the presence of the Kv7 channel blocker, linopirdine (10 $\mu \mathrm{M}$; Sigma).

\section{Real-Time Quantitative PCR ( $q P C R$ )}

We quantified relative expression of the Kcne1-5 and Kcnq1-5 isoforms in the mesenteric arteries of male and female $\mathrm{Kcne}^{+/+}$ and $\mathrm{Kcne}^{-/-}$mice by qPCR analysis, as we described previously [5]. Briefly, RNA was extracted with the RNeasy micro extraction kit, including a DNase treatment, according to the manufacturer's instructions (Qiagen). The Nanoscript 2 kit (PrimerDesign Ltd., Southampton, UK) was used to reverse-transcribe the RNA. The cDNA samples (at a concentration of $1.5 \mathrm{ng} / \mu \mathrm{l}$ ) were used for quantitative analysis of Kcne transcript expression using Precision PLUS-iC SYBR mastermix (PrimerDesign Ltd.) in 20- $\mu$ l samples containing $5 \mu \mathrm{l}$ of $\mathrm{cDNA}$ and $300 \mathrm{nM}$ primer. Experiments were run with the following cycling conditions: initial activation at $95^{\circ} \mathrm{C}$ for $10 \mathrm{~min}$, followed by 40 cycles of $95^{\circ} \mathrm{C}$ for $15 \mathrm{~s}$ and $60^{\circ} \mathrm{C}$ for 1 min on a CFX96 real-time PCR detection system (Bio-Rad, UK), 
Table 1. Kcne and Kcnq primers used for real-time qPCR experiments

\begin{tabular}{|c|c|c|c|c|}
\hline Gene & $\begin{array}{l}\text { Primer sequence, } \\
(+) \text { sense/(-) antisense }\end{array}$ & $\begin{array}{l}\text { GenBank } \\
\text { accession No. }\end{array}$ & $\begin{array}{l}\text { Amplicon, } \\
\text { bp }\end{array}$ & $\begin{array}{l}\text { Region } \\
\text { spanned }\end{array}$ \\
\hline Kcne1 & $\begin{array}{l}\text { (+) 5'-ACTCGCACGACCCTTTCA-3' } \\
\text { (-) 5'-TTTCAATGACATAGCAAGCTCTG-3' }\end{array}$ & NM_012973 & 114 & $284-397$ \\
\hline Kcne2 & $\begin{array}{l}\text { (+) 5'-TGTCATTTAAGTCCATTCCAATCAT-3' } \\
\text { (-) 5'-TGAGAAAGAAGGTTGAAAGATTTGT-3' }\end{array}$ & NM_133603 & 116 & $769-884$ \\
\hline Kcne3 & $\begin{array}{l}\text { (+) 5'-TTATGATGTCTGAGGATTGTCTTCT-3' } \\
\text { (-) 5'-TGACCTAACTCTCTTACCAATTTCT-3' }\end{array}$ & NM_022235 & 114 & $449-562$ \\
\hline Kcne4 & $\begin{array}{l}\text { (+) 5'-CCCTTGAGTCCCATGTGTCT-3' } \\
(-) 5^{\prime} \text {-GTAGCCCAGCATGATTCCAAT-3' }\end{array}$ & NM_212526 & 113 & $135-247$ \\
\hline Kcne5 & $\begin{array}{l}\text { (+) 5'-GTCAACGGCGTCCTGGAG-3' } \\
(-) 5^{\prime} \text {-CAGCAGCAAGCGGTTCAA-3' }\end{array}$ & NM_00110100 & 96 & $27-122$ \\
\hline Kcnq1 & $\begin{array}{l}\text { (+) 5'-CTCGGAGTCACACGCTTCT-3' } \\
(-) 5^{\prime} \text {-GCTTGAACTTCTTCTTCTTTACCAT-3' }\end{array}$ & NM_008434 & 75 & $1,301-1,375$ \\
\hline Kcnq2 & $\begin{array}{l}\text { (+) 5'-CCCTCATTGGTGTCTCGTTCT-3' } \\
(-) \text { 5'-GGTTCCGCCGTTTCTCAAAG-3 }\end{array}$ & NM_010611 & 111 & $1,026-1,136$ \\
\hline Kcnq3 & $\begin{array}{l}\text { (+) 5'-GAAGAGGGGCAGAGGAGGA-3' } \\
(-) 5^{\prime} \text {-CCTGTACTTGGCGTTGTTCC-3' }\end{array}$ & NM_152923 & 93 & $226-318$ \\
\hline Kcnq4 & $\begin{array}{l}\text { (+) 5'-GTGGTCTTTGGCTTGGAGTATAT-3' } \\
(-) 5^{\prime} \text {-CGATGACACAGAAGGGTTTCC-3' }\end{array}$ & NM_001081142 & 112 & $424-535$ \\
\hline Kcnq5 & $\begin{array}{l}\text { (+) 5'-GTCAGATAAGAAGAGCCGAGAGA-3' } \\
(-) \text { 5'-CGATGGACTGGACCTGTTTCT-3' }\end{array}$ & NM_001160139 & 107 & $2,164-2,270$ \\
\hline
\end{tabular}

and data was collected during each cycling phase. Melt-curve analysis completed the protocol. RNA samples that were reverse-transcribed without the nanoscript enzyme and no-template controls (NTCs) were run alongside all reactions to assess contamination. Quantification cycle $(\mathrm{Cq})$ values were determined using Bio-Rad CFX96 Manager v3.0 software. The optimal reference genes were $\beta$-actin and cytochrome c- 1 as determined by geNorm analysis (Biogazelle). The expression levels of the Kcne isoform transcripts were calculated relative to these reference genes in each artery to give a relative isoform expression profile using $2^{-\Delta \mathrm{Cq}}$ [24]. All primer assays were obtained from PrimerDesign Ltd. and the sequences for the Kcne1-5 and Kcnq1-5 primers are given in table 1.

\section{Western Blotting}

We homogenized approximately 5-mm-long mouse mesenteric artery tissue samples ( 1 sample each from 4-5 different mice per sex per genotype) in $100 \mu \mathrm{l}$ of $\mathrm{PBS}$ ( $\mathrm{pH} 7.5$ ) containing protease inhibitor cocktail (Thermo Fisher, Waltham, Mass., USA) and $10 \%$ SDS (w/v) using a motorized Eppendorf homogenizer. Samples were then centrifuged for $10 \mathrm{~min}$ at $3 \mathrm{~g}$ at room temperature (to avoid solidification arising from the high SDS content). The supernatants were resuspended in LDS gel loading buffer (Thermo Fisher) containing $25 \mathrm{~mm}$ Tris(2-carboxyethyl)phosphine, heated for $10 \mathrm{~min}$ at $65^{\circ} \mathrm{C}$, vortexed, centrifuged for $3 \mathrm{~min}$ at $5 \mathrm{~g}$, and then separated by SDS-PAGE. Proteins were transferred to PVDF membranes and Western-blotted with 1/500 rabbit polyclonal anti-KCNQ4 (Santa Cruz Biotechnology, Dallas, Tex., USA) and 1/1,000 rabbit polyclonal anti-GAPDH (Abcam, Cambridge, UK) antibodies, with chemiluminescent detection via 1/5000 HRPconjugated goat anti-rabbit IgG secondary antibodies (BioRad,
Hercules, Calif., USA). Band densities were quantified using ImageJ software (NIH, Bethesda, Mass., USA) and Kv7.4 band density values each normalized to same-lane GAPDH band density.

\section{Statistical Analysis}

Results are shown as means \pm SEM, unless otherwise stated. $\mathrm{p}<$ 0.05 was taken as showing significant differences between means. Individual $\log \mathrm{EC}_{50}$ values (fig. 1c, 2c) were calculated using a standard slope, equal to a Hill slope (or slope factor) of 1.0 for methoxamine and -1.0 for ML213. Differences between means were assessed for statistical significance with unpaired Student's t tests. A two-way ANOVA followed by a Bonferroni posttest was used to determine the significance of linopirdine on the isoprenaline-concentration effect curves and to compare the effect of isoprenaline between $\mathrm{Kcne}^{+/+}$ and $\mathrm{Kcne}^{-/-}$male and female mice. Unpaired Student's $\mathrm{t}$ tests were used to compare changes in specific KCNE and KCNQ isoform transcript expression. ANOVA with the post hoc Tukey HSD test was used to compare Kv7.4 Western blot band densities.

\section{Results}

Application of sequentially increasing concentrations of the $a$-adrenoceptor agonist, methoxamine, caused a similar concentration-dependent constriction of mesenteric artery segments from both female $(n=8)$ and male $(\mathrm{n}=6) \mathrm{Kcne}^{+/+}$mice, with mean $\operatorname{LogEC}_{50}$ values of -5.2 $\pm 0.05 \mathrm{M}$ and $-5.2 \pm 0.05 \mathrm{M}(\mathrm{p}=0.31$, according to an un- 


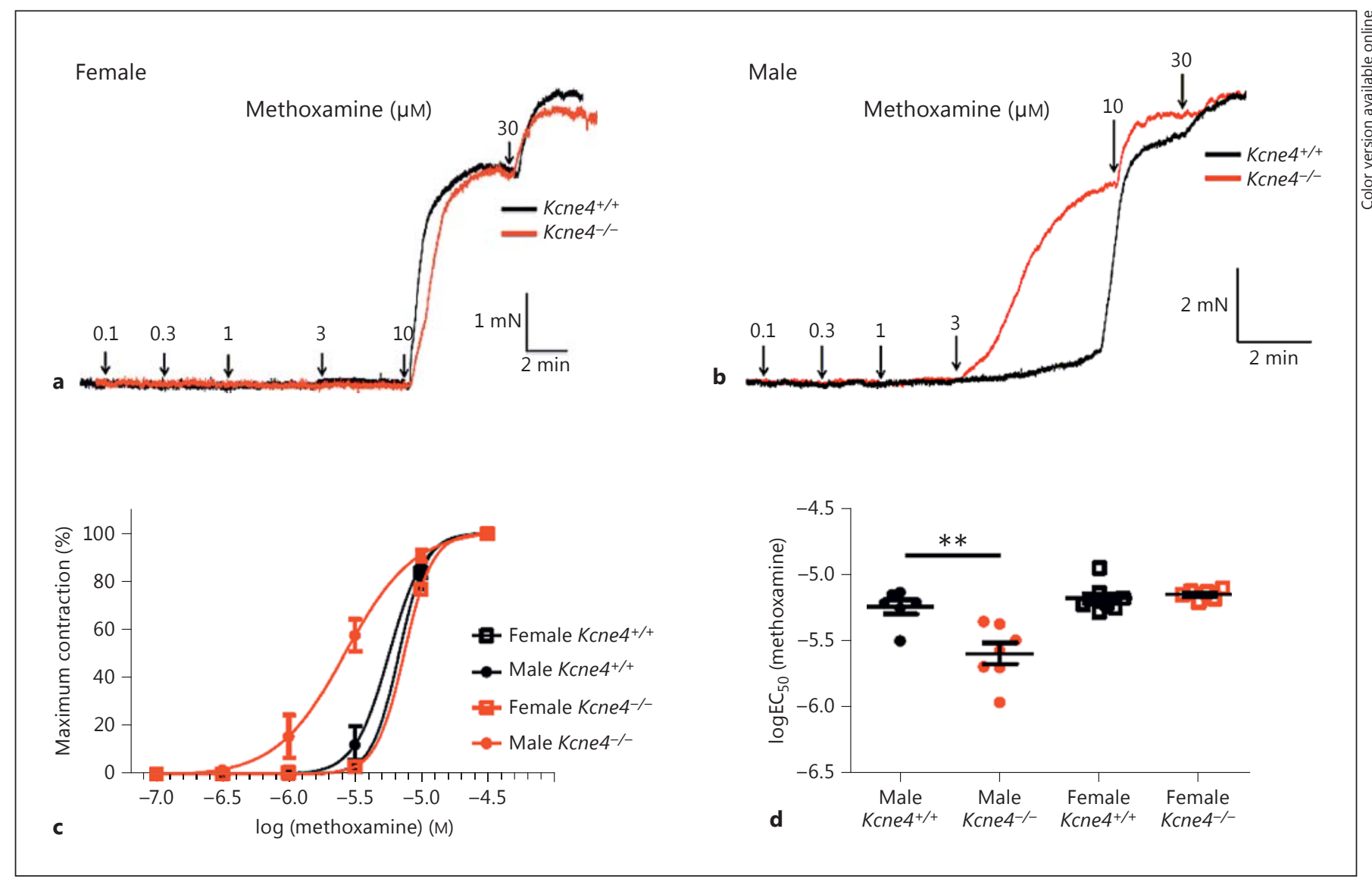

Fig. 1. Effect of methoxamine on male and female mesenteric arteries from $\mathrm{Kcne}^{+/+}$and $\mathrm{Kcne}^{-{ }^{--}}$mice. Representative isometric tension recordings from female (a) and male (b) Kcne $4^{+/+}$(black lines) and Kcne $4^{-/-}$(red lines; color refers to the online version only) to sequentially increasing concentrations of methoxamine. c Mean concentration-effect curves to methoxamine. $\mathbf{d}$ Scatter plot of the $\mathrm{EC}_{50}$ values to methoxamine. $\mathrm{n}=6-8 .{ }^{* *} \mathrm{p}<0.001$, unpaired $t$ test.

paired $t$ test), respectively (fig. 1). In addition, the maximum force developed by the female and male artery segments did not differ significantly $(4.3 \pm 0.46 \mathrm{mN}$ and 4.5 $\pm 0.53 \mathrm{mN}$, respectively; $\mathrm{p}=0.75$, according to an unpaired $t$ test). In the females, the response of mesenteric artery segments from the $\mathrm{Kcne}^{-/-}$mice to methoxamine $\left(\operatorname{LogEC} \mathrm{C}_{50}\right.$ of $-5.1 \pm 0.01 \mathrm{M}$ ) was not significantly different from that of the $\mathrm{Kcne}^{+/+}$females ( $\mathrm{p}=0.53$, according to an unpaired t test; fig. $1 \mathrm{c}, \mathrm{d}$ ). In contrast, segments of mesenteric artery from male $\mathrm{Kcne}^{-{ }^{--}}$mice $(\mathrm{n}=6)$ were significantly more sensitive to increasing concentrations of methoxamine $\left(\operatorname{LogEC} \mathrm{C}_{50}\right.$ of $-5.6 \pm 0.08 \mathrm{M} ; \mathrm{p}=0.006$, according to an unpaired t test) compared to the $\mathrm{Kcne}^{+/+}$ mesenteric arteries (fig. 1c, d); however, the maximum force developed at 30- $\mu \mathrm{M}$ methoxamine was not different in mesenteric artery segments between the male $\mathrm{Kcne}_{4}^{+/+}$ and $\mathrm{Kcne}^{-/-}$mice $(4.6 \pm 0.89 \mathrm{mN} ; \mathrm{p}=0.97$, according to an unpaired $t$ test).

Application of ML213 produced concentration-dependent relaxations that were not different in the mesenteric artery from the male and female $\mathrm{Kcne}^{+/+}$mouse ( $p=0.24$ by unpaired $t$ test; fig. 2 ). In the females, there was no significant difference of vascular reactivity to ML213 in the Kcne4 ${ }^{-/-}$mice $(\mathrm{n}=6)$ compared to the $K c n e 4^{+/+}$mice ( $\mathrm{n}=5$; fig. $2 \mathrm{c}, \mathrm{d}$ ). In contrast, Kcne4 deletion in the mesenteric artery segments of male mice shifted the $\log \mathrm{EC}_{50}$ for vascular response to ML213 from $-6.01 \pm 0.1 \mathrm{M}\left(\mathrm{Kcne}^{+/+}, \mathrm{n}=5\right)$ to $-5.7 \pm 0.04 \mathrm{M}\left(\mathrm{Kcne}^{-/-}\right.$, $\mathrm{n}=6 ; \mathrm{p}=0.005$ in unpaired $\mathrm{t}$ test; fig. $2 \mathrm{c}, \mathrm{d})$.

As previously reported, isoprenaline-induced relaxations are mediated, in part, by Kv7 channels [11]. Figure 3 shows that isoprenaline caused robust, concentration- 


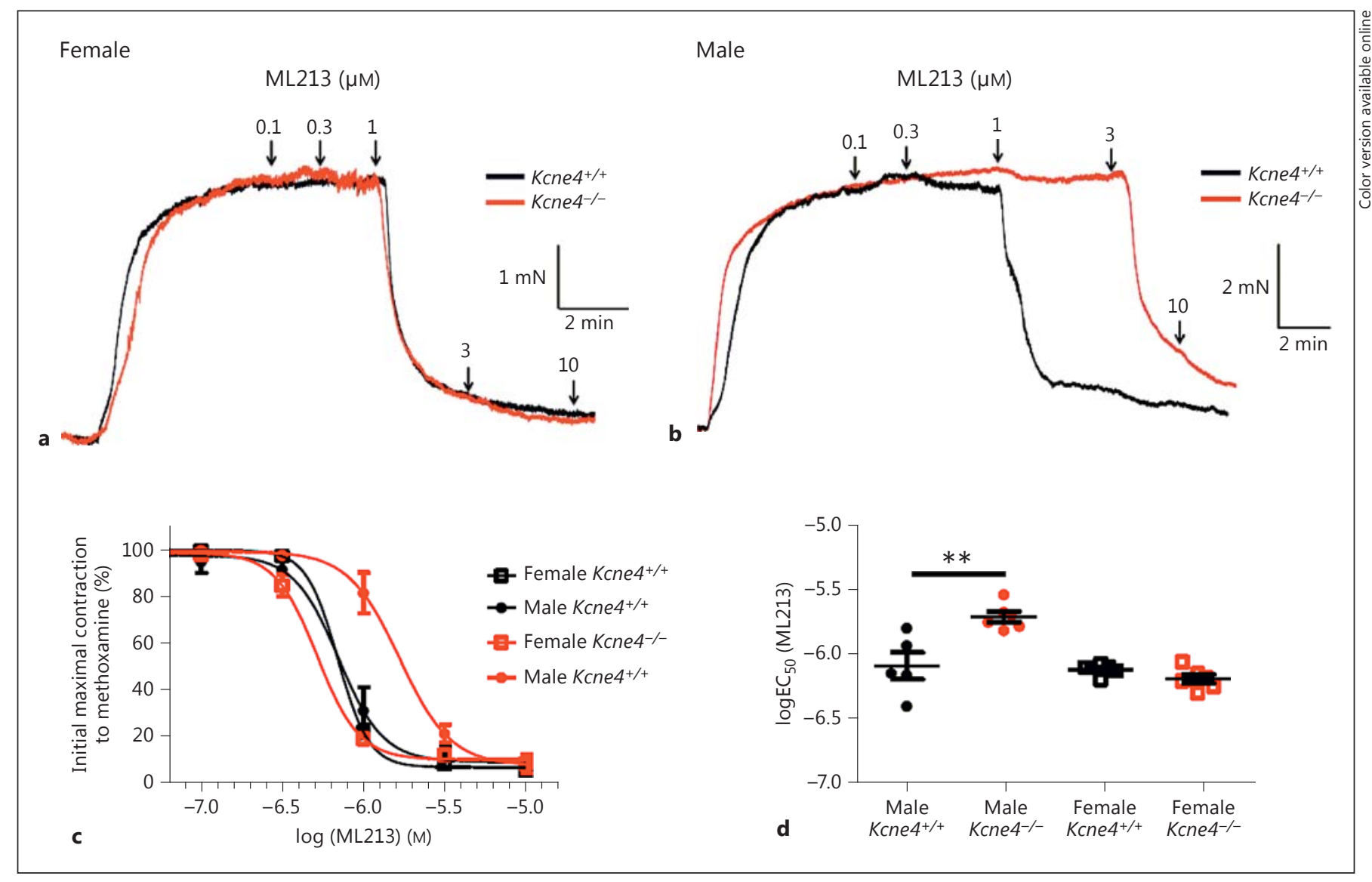

Fig. 2. Effect of ML213 on female and male mesenteric arteries from $\mathrm{Kcne}^{+/+}$and $\mathrm{Kcne}^{-{ }^{--}}$mice precontracted with methoxamine. Representative isometric tension recordings from female (a) and male (b) Kcne $4^{+/+}$(black lines) and $\mathrm{Kcne}^{-/-}$(red lines; color refers to the online version only) to sequentially increasing concentrations of ML213 (0.1-10 $\mu \mathrm{M})$. c Mean concentration-effect curves to ML213. d Scatter plot of the EC 50 values to ML213. $\mathrm{n}=5-6 .{ }^{* *} \mathrm{p}<0.001$, unpaired $\mathrm{t}$ test.

dependent relaxations in precontracted mesenteric artery segments from the $\mathrm{Kcne}^{+/+}$male and female mice that were not statistically different between the sexes. In both male (fig. 3a) and female (fig. 3b) $\mathrm{Kcne}^{+/+}$mouse mesenteric arteries, the isoprenaline relaxations were inhibited by linopirdine $(10 \mu \mathrm{M} ; \mathrm{n}=5-6)$.

We next determined the impact of Kcne4 deletion on isoprenaline-mediated relaxations in mesenteric arteries from male and female mice. Isoprenaline was markedly less effective at relaxing the mesenteric arteries of $\mathrm{Kcne}^{-/-}$male and female mice ( $>2$-fold less relaxation at 1 and $3 \mu \mathrm{M}$ isoprenaline compared to $\mathrm{Kcne}^{+/+} ; \mathrm{p}<0.05 ; \mathrm{n}=4-8$; fig. 4).

We next employed qPCR to quantify the expression of Kcne1-5 and Kcnq1-5 isoform transcripts using mesenteric artery cDNA from male and female $\mathrm{Kcne}^{+/+}$and $\mathrm{Kcne}^{-/-}$mice (fig. 5). Expression of Kcne4 was $>2$-fold higher in male mouse mesenteric artery tissue compared to that of the female mice ( $\mathrm{n}=7 ; \mathrm{p}=0.0061$ by unpaired $\mathrm{t}$ test). Kcne1 was detectable in 5 of 7 female mesenteric artery samples but not detectable in any male mouse mesenteric arteries ( $\mathrm{n}=7 ; \mathrm{p}=0.016$ by unpaired t test). Kcne 3 displayed the highest levels of expression, and, as also observed for Kcne 2 and Kcne5, this expression level was sexindependent (fig. 5a). As expected, Kcne4 transcript was not detectable in $\mathrm{Kcne}^{-/-}$mesenteric arteries from either sex, confirming efficient germline deletion (fig. 5b, c). Kcne4 deletion was associated with an approximately $50 \%$ increased expression of the already highly expressed Kcne 3 transcript in both male and female mice, which was significant in the male $(\mathrm{n}=6 ; \mathrm{p}=0.006)$ but not the female mesenteric arteries $(n=6 ; p=0.104$; fig. 5b, c). Kcne4 deletion was not associated with any other changes in other 

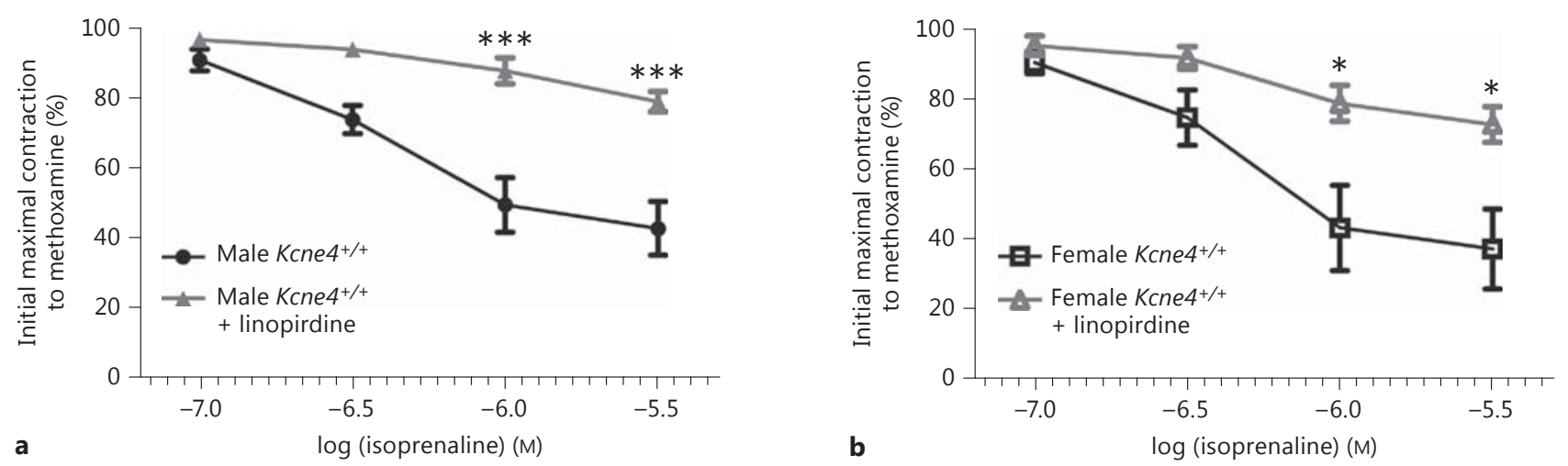

Fig. 3. Effect of the Kv7 channel blocker, linopirdine (grey), on the vasorelaxant effect of isoprenaline in 6 male (a) and 5 female (b) $\mathrm{Kcne}^{+/+}$mesenteric arteries. ${ }^{*} \mathrm{p}<0.05$ and ${ }^{* * *} \mathrm{p}<0.001$, two-way ANOVA followed by a Bonferroni post hoc test.

Fig. 4. Effect of isoprenaline on male and female mesenteric arteries from $\mathrm{Kcne}^{+/+}$ and $\mathrm{Kcne}^{-/-}$mice. Mean concentrationeffect curves to isoprenaline $(\mathrm{n}=4-8)$. A two-way ANOVA followed by a Bonferroni post hoc test compared the effect of isoprenaline in $\mathrm{Kcne}^{+/+}$(black) with the $\mathrm{Kcne}^{-{ }^{--}}$(red; color refers to the online version only) in both sexes. Significance is denoted by $*$ for females and $\S$ for males.

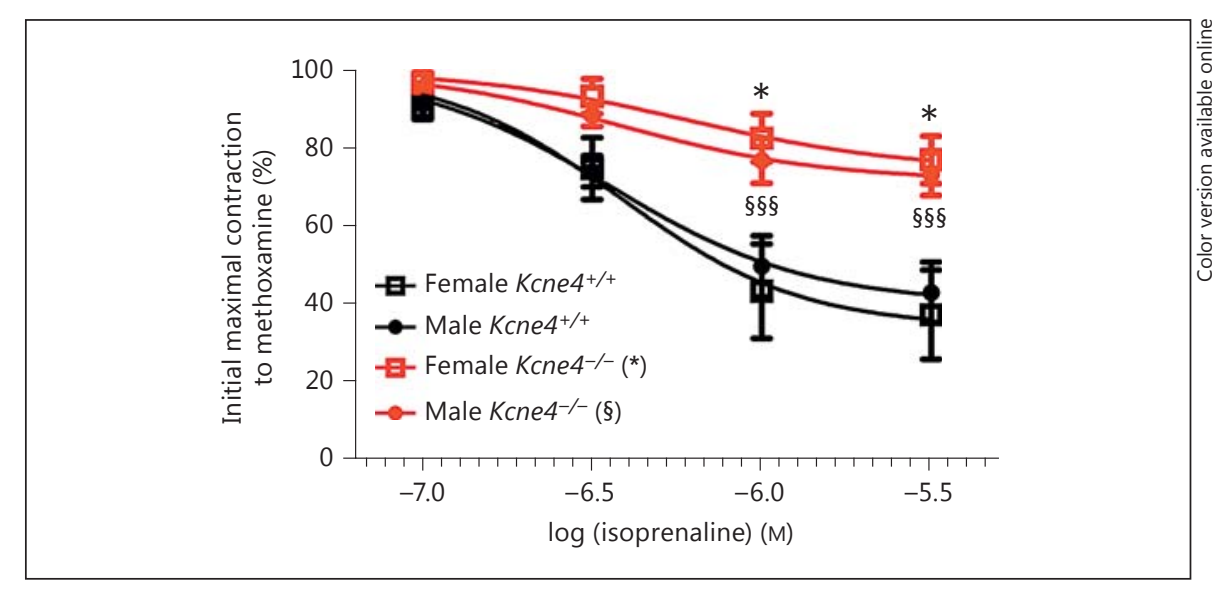

Kcne isoform expression in male or female mouse mesenteric arteries (fig. 5b, c). We also analyzed expression of Kcnq1-5 transcripts in male and female $\mathrm{Kcne}^{+/+}$and Kcne $4^{-/-}$mice mesenteric arteries. There was no change in Kcnq transcript expression between $\mathrm{Kcne}^{+/+}$male and female mesenteric arteries $(n=6$; fig. $6 a)$, nor did we detect any change in Kcnq transcript expression in $\mathrm{Kcne}^{+/+}$ mice compared to $\mathrm{Kcne}^{-/-}$in both male and female mice $(\mathrm{n}=6$; fig. 6b, $\mathrm{c}$ ).

In contrast, Kcne 4 deletion reduced Kv7.4 protein expression. Kv7.4 protein expression in mouse mesenteric artery tissue preparations from female mice was double that observed in male mice $(\mathrm{p}<0.05)$, and was reduced in both sexes by Kcne4 deletion (fig. 7a, b), with the comparison for female $\mathrm{Kcne}^{+/+}$versus male or fe- male Kcne $4^{-1-}$ mice achieving statistical significance by ANOVA after the Tukey HSD test ( $\mathrm{p}=0<0.01$; fig. $7 \mathrm{~b}$ ).

\section{Discussion}

This is the first study to identify sex-dependent differences in the function and expression levels of an ion channel ancillary subunit in the vasculature. Our findings show that Kcne4 expression is higher, and functional effects of its deletion more striking, in the mesenteric arteries of male mice compared to female mice. Using a $\mathrm{Kcne}^{-/-}$mouse line, we found that targeted germline Kcne4 deletion renders male but not female mouse mesenteric arteries more sensitive to $\alpha$-adren- 
Fig. 5. Real-time quantitative PCR analysis comparing Kcne1-5 mRNA expression in male and female $\mathrm{Kcne}^{+/+}$mice (a) and $\mathrm{Kcne}^{+/+}$compared to Kcne $4^{-/-}$in male (b) and female $(\mathbf{c})$ mice $(\mathrm{n}=5-6) .{ }^{*} \mathrm{p}<0.05$, ** $\mathrm{p}<0.01$ and ${ }^{* * *} \mathrm{p}<0.001$, unpaired $\mathrm{t}$ tests.
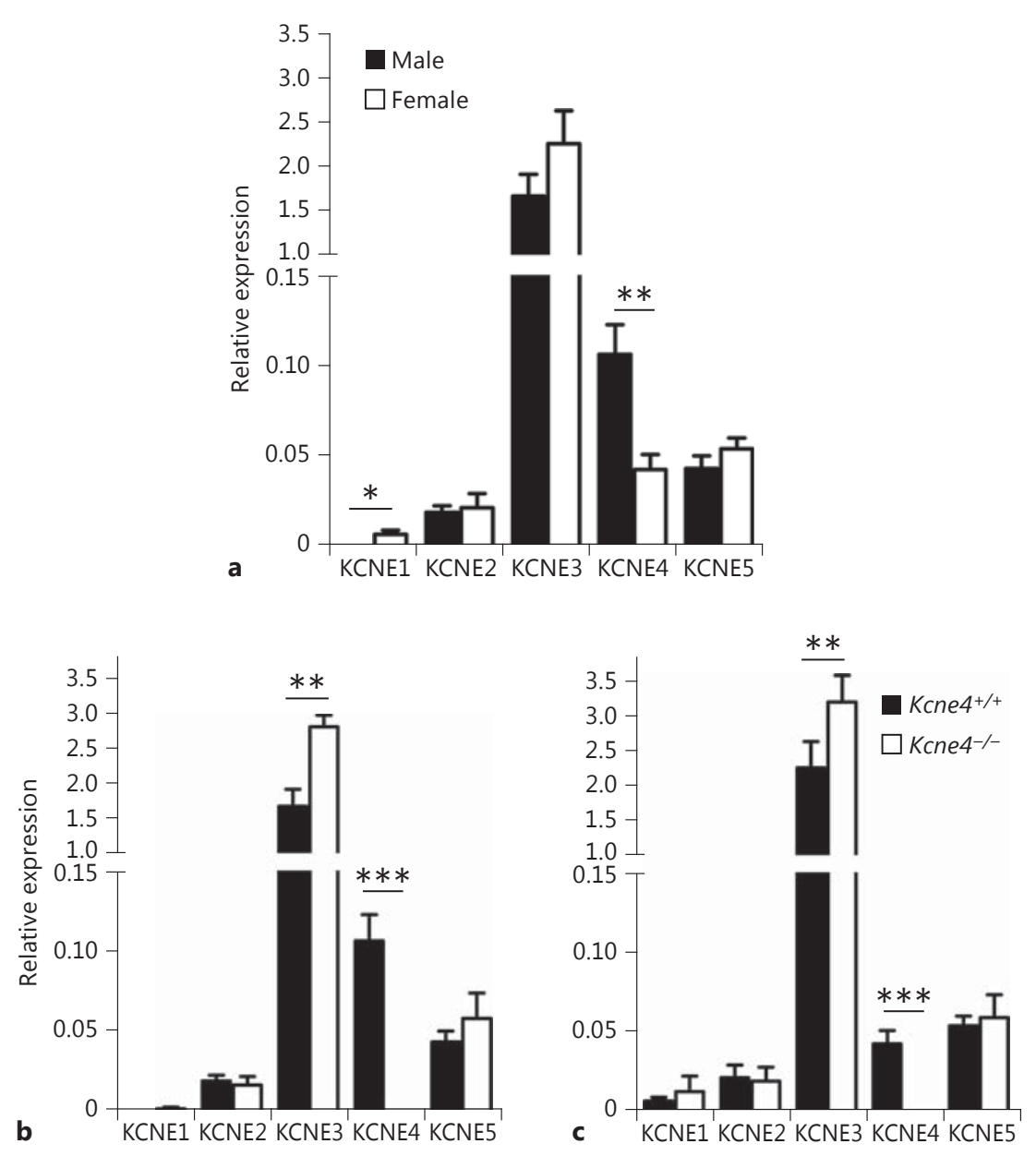

ergic stimulation and less responsive to the Kv7.2-7.5 activator, ML213. These data suggest that males are more sensitive to changes in Kcne4 expression in the vasculature than females. However, responses to the $\beta$-adrenoceptor agonist, isoprenaline, were inhibited in both male and female $\mathrm{Kcne}^{-/-}$mice, suggesting that Kcne4 is important in mediating the effects of this receptor in both sexes.

Kv7 channels, particularly Kv7.4 and Kv7.5, are important regulators of vascular tone $[3,6-15,25,26]$. These channels have been shown extensively to be expressed and functionally important in several human and rodent arteries. We previously reported that KCNE4 is expressed in several arteries, and that targeted KCNE4 knockdown in male rat mesenteric arteries using a morpholino strategy depolarized the smooth muscle resting-membrane potential and reduced vasorelaxations in response to a Kv7.27.5 activator (S-1) [2]. We found that KCNE4 coassembles with Kv7.4 and Kv7.5 in mesenteric myocytes, left-shifting the voltage-dependence of Kv7.4 channel activation and increasing Kv7.4 membrane expression [2]. Our findings here, using male $\mathrm{Kcne}^{-1-}$ mice, confirm these previous findings and highlight the crucial regulatory role KCNE4 has on vascular Kv7 channel function in male mesenteric arteries. Importantly, this study uncovers a novel role for the KCNE4 subunit in mediating $\beta$-adrenoceptor responses in the mesenteric artery. Kv7 channels in the vasculature contribute to different Gs-coupled-receptor-mediated relaxations, yet the exact signaling mechanisms are still unclear $[7,11,12,14,15]$. Following Gscoupled-receptor activation, a cAMP-dependent mechanism [11] and the $\beta \gamma$-subunits [15] have both been shown to enhance Kv7.4/Kv7.5 channel activity. This study confirms that the isoprenaline effects in the mesenteric artery are sensitive to Kv7 blockade (linopirdine) and reveals an important role for KCNE4 in mediating these vasorelax- 


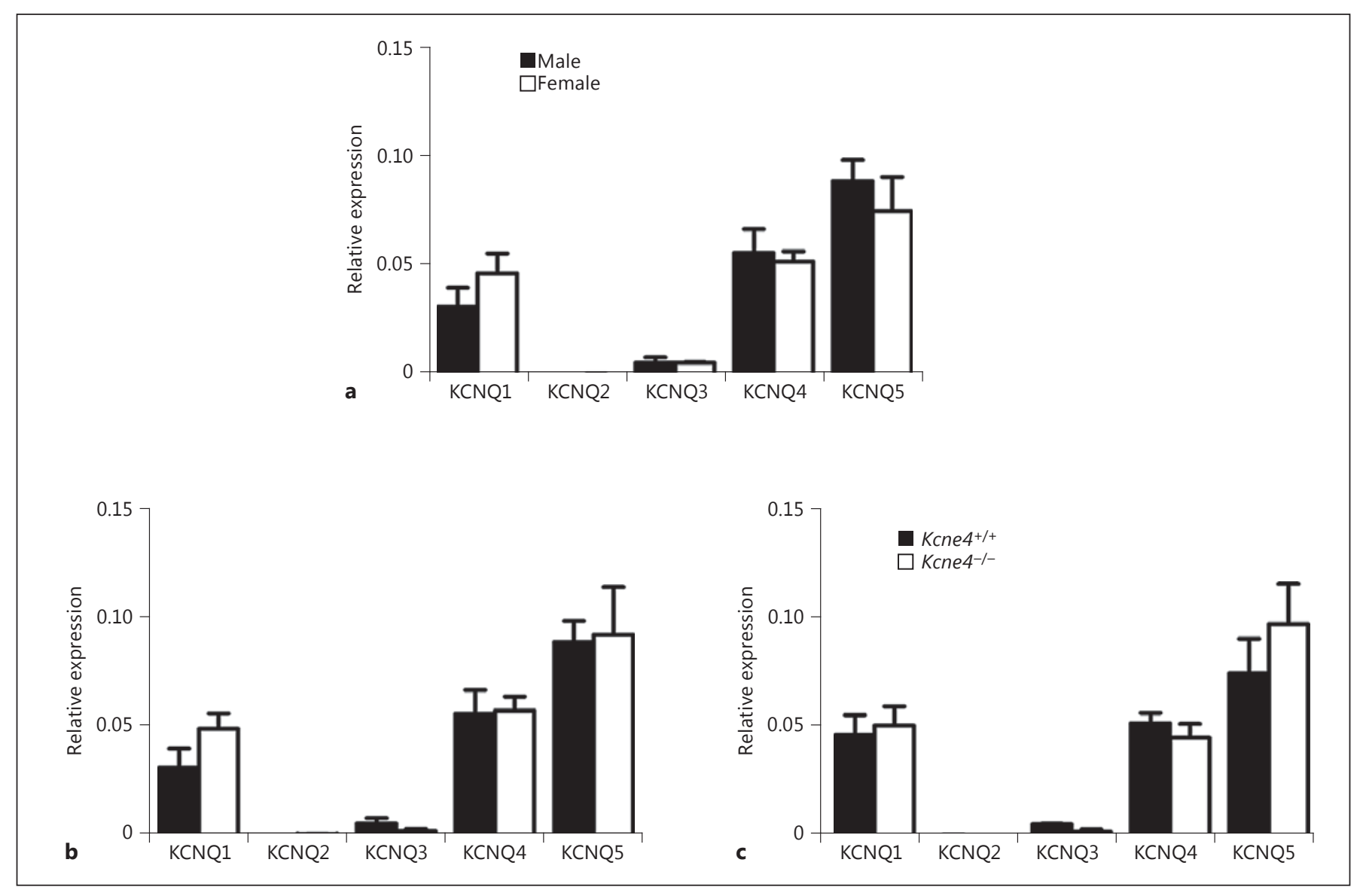

Fig. 6. Real-time quantitative PCR analysis comparing Kcnq1-5 mRNA expression in male and female Kcne $4^{+/+}$ mice (a) and $\mathrm{Kcne}^{+/+}$compared to $\mathrm{Kcne}^{-/-}$in male (b) and female (c) mice $(\mathrm{n}=5-6)$.

ant effects in the mesenteric arteries of both males and females. Although Kv7 channel function was unaffected in the female $\mathrm{Knne}^{-/-}$mice, it is interesting that the responses to isoprenaline were equally impaired in the male and female $\mathrm{Kcne}^{-/-}$mice. These data suggest the $\beta$-adrenoceptor intracellular signaling relies on KCNE4 to activate the vascular Kv7 channels. Interestingly, the KCNE4 protein contains a consensus cAMP phosphorylation site and a putative $\beta \gamma$-binding site [27] in close proximity to one another (amino acids 61-68; accession EAW70810.1) on the C-terminus; however, understanding the mechanisms by which the KCNE4 subunit interacts with Kv7.4 to facilitate the receptor-mediated vasorelaxant effects requires future attention.

Recently, we found that the KCNE4 $\beta$-subunit is positively regulated by DHT in the mouse cardiac myocytes [23]. Male $\mathrm{Kcne}^{+/+}$mice were shown to have a higher $\mathrm{Kv}$ current density compared with their age-matched, pre- menopausal female counterparts. The $\mathrm{Kcne}^{-/-}$mice (males and females) had the same Kv current density as the $\mathrm{Kcne}^{+/+}$females. Kcne4 deletion did not alter ventricular repolarization in premenopausal female mice, but it delayed ventricular repolarization in postmenopausal female mice, which, unlike premenopausal female mice, showed ventricular Kcne4 expression levels equivalent to those of adult male mice [23]. Interestingly, in this study, we found no sex-dependent differences in the $\mathrm{Kcne}^{+/+}$mouse mesenteric artery responses to methoxamine, isoprenaline or ML213, even though Kcne4 mRNA expression in the male mouse mesenteric arteries was more than double that of the females. Although posttranscriptional modifications are possible, when taken together with the finding that the female $\mathrm{Kcne}^{-1-}$ mice showed similar responses to ML213 as their $\mathrm{Kcne}^{+/+}$ counterparts, these data suggest that female mice are less reliant on KCNE4 to regulate Kv7 channels in the vascu- 


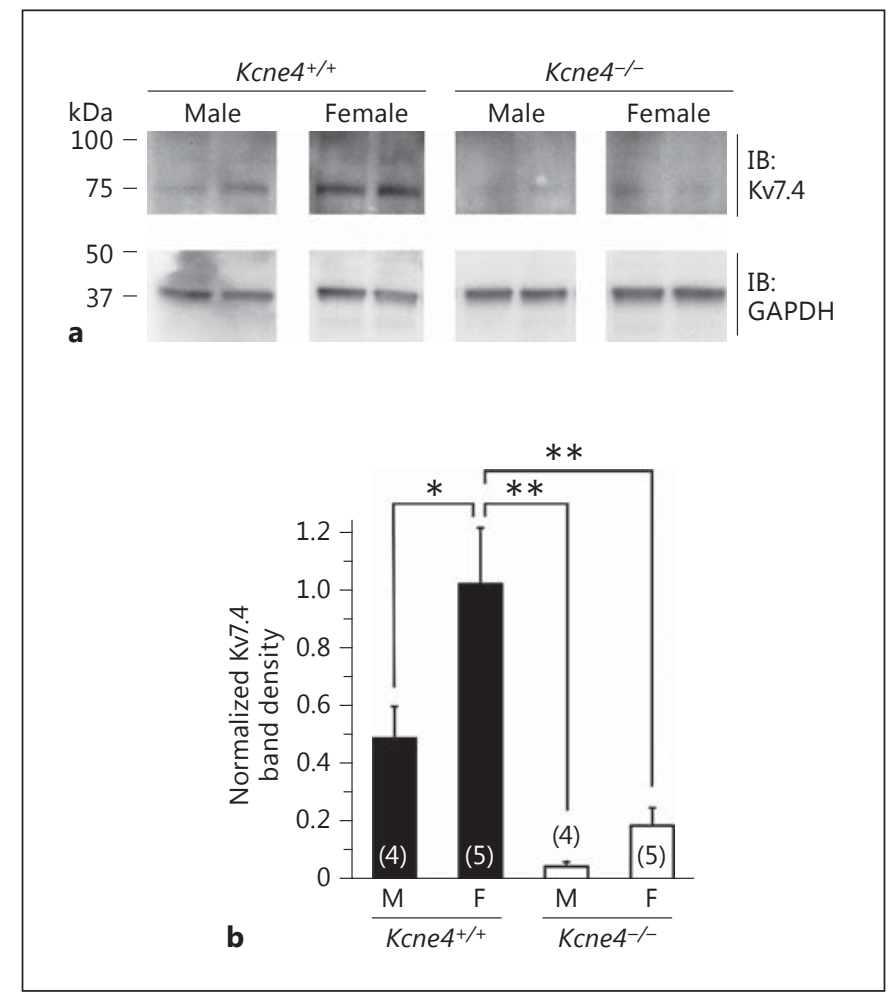

Fig. 7. Effects of sex and Kcne4 deletion on mouse mesenteric artery Kv7.4 protein expression. a Exemplar Western blots showing Kv7.4 (upper) and GAPDH (lower) expression in mouse mesenteric arteries. b Mean Kv7.4 band densities, normalized to samelane GAPDH band densities, for blots as in $\mathbf{a}(\mathrm{n}=4-5$ mice per group, as indicated in parentheses). ${ }^{*} \mathrm{p}<0.05,{ }^{* *} \mathrm{p}<0.01$, ANOVA with the Tukey HSD test.

lature, possibly relying on other Kcne isoforms. Aside from Kcne4, the only Kcne isoform to exhibit sex-dependent expression levels here was Kcne1. As reported previously $[5,28]$, Kcne1 mRNA was not detected here in the mesenteric arteries of male mice; however, it was expressed in some of the female mesenteric arteries (fig. 5a). KCNE1 reportedly increases Kv7.4 [5, 29] and Kv7.5 [30] currents in vitro. Based on these in vitro findings, one might expect KCNE1 to increase the function of the vascular Kv7.4/Kv7.5 channel, which could explain why the vascular responses to methoxamine and ML213 were normal in the female $\mathrm{Kcne}^{-1-}$ mice. The effect of KCNE1 on the Kv7.4/7.5 heteromeric channel that is likely to be found in the vascular smooth muscle is yet to be determined; however, given the findings presented in this paper, the role of KCNE1 in the vasculature may be worth further exploration. Furthermore, the qPCR data in this study identified Kcne3 mRNA as predominant in both male and female mesenteric arteries, and upregulated by approximately $50 \%$ in males in response to Kcne4 deletion. As the Kcne3 expression levels in $\mathrm{Kcne}^{+/+}$and $\mathrm{Kcne}^{-/-}$mice were not sex-dependent, we consider it unlikely that Kcne3 underlies sex-specific differences in mouse mesenteric artery reactivity. However, we previously found that Kcne3 was upregulated in the gastric epithelium in response to germline Kcne2 deletion and that this resulted in mistrafficking of Kcnq1 to the basolateral side of parietal cells, where it could not perform its normal function of recycling $\mathrm{K}^{+}$back into the stomach lumen [31]. In addition, KCNE3 suppresses currents produced by Kv7.4 [29]. It will, therefore, be interesting in the future to examine the possible functional effects of vascular Kcne3 remodeling in response to Kcne4 deletion.

Vascular diseases are, in general, more common in males than females, but the precise mechanisms responsible for these differences are incompletely understood. The effects of sex hormones in the cardiovascular system are thought be one important determinant of these differences $[17,18,22]$. One factor that has been extensively researched in the vasculature is the male sex hormone, testosterone $[22,32]$. Together with higher levels of circulating testosterone, males have a higher incidence of vascular disease; however, reduced testosterone levels in aging men are known to increase the risk of developing cardiovascular diseases [33-35]. Therefore, it is still unclear whether testosterone is a positive or negative factor in determining susceptibility to cardiovascular diseases.

The expression levels of $K C N E$ transcripts and protein can be subject to regulatory influences, particularly by androgens such as estrogen and testosterone, in at least some tissues. As mentioned, Kcne4 transcript is positively regulated by DHT in mouse ventricular myocardium to the extent that it dictates sex-specific functional differences in ventricular repolarization currents [23]. Kcne2 is upregulated by estrogen via a genomic mechanism [36], and may act as the female equivalent of Kcne4 with respect to aspects of ventricular function, as both Kcne2 and Kcne4 regulate Kv4.2 and Kv1.5 channels in mouse ventricular myocytes $[23,37]$. Kcne3 protein expression in rat colonic crypts is reportedly reduced by estrogen via a nongenomic action involving Kcne3 serine 82 [38], a PKC phosphorylation site [39]. This activity may affect colonic Kv7.1-KCNE3 current properties and density during the estrus cycle [38]. In future work, it will be important to define the different roles and interaction partners of all the KCNE subunits in the regulation of smooth muscle contractility, and investigate the possible role of sex hormones in regulating the vascular expression of 
both the KCNEs and their a-subunit partners, and the potentially dynamic effects of this on vascular reactivity. An important aspect of this will be to determine how the female mesenteric arteries compensate for loss of Kcne4; is it simply less important in females and so compensation is easier, for example? Our Kv7.4 Western blot results may provide some clues. These data suggest that Kv7.4 protein expression or stability in mouse mesenteric artery is reduced by Kone4 deletion, which is reminiscent of recent findings that transient KCNE4 knockdown in the rat mesenteric artery impairs Kv7.4 surface expression [2]. In addition, Kv7.4 protein was higher in mesenteric arteries isolated from female mice compared to those from males. This was despite the lack of a sex-dependent difference in KCNQ4 transcript (which encodes Kv7.4) expression, an apparent discrepancy that could be explained by, for example, the posttranslational effects of hormones, as previously reported for KCNE3 in the rat colon [39], described above. These findings raise the interesting possibility that, in contrast to males, female mouse mesenteric arteries maintain enough Kv7.4 protein to ensure proper Kv7 channel function following the destabilizing effects of Kcne4 deletion. Regardless, this study emphasizes that, in future experiments, both sexes should be considered when determining the vascular roles of KCNE subunits.

Previously, Zhou et al. [40] showed that testosterone deprivation reduced Kv currents in rat aortic myocytes, which was associated with decreased Kv1.5 expression. We previously found that castration DHT-dependently reduced ventricular myocyte Kcne4 expression, and that lower Kcne4 expression was associated with lower Kv1.5 current [23]. It is possible that Kcne4 deletion could affect ion channels other than Kv7.4 in the mesenteric artery, including Kv1.5; however, in this study, we focused on its regulation of the Kv7 channels, as this interaction had been previously reported in the vasculature. It will be important in future experiments to determine other possible a-subunits with which KCNE4 might coassemble, to ful- ly understand the impact of DHT (or other androgen)mediated changes in KCNE4 expression.

In summary, our findings highlight fundamental sex differences in the sensitivity of expression changes in KCNE4 in the vasculature, with important implications for vascular reactivity. These findings are in line with our previous studies that showed KCNE4 is regulated by DHT in mice, and that KCNE4 is an important regulator of Kv7.4 vascular function in male rats. We also provide novel evidence that KCNE4 is involved in the Kv7 channel recruitment following isoprenaline-induced activation of $\beta$-adrenoceptors. Given the important regulatory role of the KCNE family, not only with respect to Kv7 channels [41] but also many other Kv channel subtypes $[42,43]$, pacemaker channels [44] and even reportedly Ltype $\mathrm{Ca}^{2+}$ channels [45], much more work needs to be done to elucidate the functional role and the implications of sex-dependent differences in the expression of the KCNE ancillary subunits in blood vessels.

\section{Acknowledgements}

We are extremely grateful to Carsten Thorndahl and James Lee Park from Danish Myo Technology for loaning a myograph to Dr. Abbott's laboratory, and to Drs. Steve Goldstein and Daniel Levy for the gift of the Kcne $4^{-/-}$mouse line. We thank Dr. Shawn Crump, Dara Nguyen and Thuyen Nguyen for technical assistance.

T.A.J. received funding from the People Programme (Marie Curie Actions) of the European Union's Seventh Framework Programme (FP7/2007-2013) under REA grant agreement No. 608765 and a grant from the Lundbeck Foundation. The Lundbeck Foundation also provided an additional travel grant for T.A.J. to travel to The University of California, Irvine, to carry out many of these experiments. G.W.A. was supported by the US National Institutes of Health (GM115189).

\section{Disclosure Statement}

The authors have no conflicts of interest to report pertaining to this study.

\section{References}

Vascular Effects of Kcne4 Deletion
1 Abbott GW, Goldstein SA: A superfamily of small potassium channel subunits: form and function of the MinK-related peptides (MiRPs). Q Rev Biophys 1998;31:357-398.

2 Jepps TA, Carr G, Lundegaard PR, Olesen SP, Greenwood IA: Fundamental role for the KCNE4 ancillary subunit in Kv7.4 regulation of arterial tone. J Physiol 2015;593:53255340 .
$3 \mathrm{Ng}$ FL, Davis AJ, Jepps TA, Harhun MI, Yeung SY, Wan A, Reddy M, Melville D, Nardi A, Khong TK, Greenwood IA: Expression and function of the K+ channel KCNQ genes in human arteries. Br J Pharmacol 2011;162: 42-53.

4 Stott JB, Jepps TA, Greenwood IA: K(V)7 potassium channels: a new therapeutic target in smooth muscle disorders. Drug Discov Today 2014;19:413-424. 
5 Jepps TA, Bentzen BH, Stott JB, Povstyan OV, Sivaloganathan K, Dalby-Brown W, Greenwood IA: Vasorelaxant effects of novel Kv 7.4 channel enhancers ML213 and NS15370. Br J Pharmacol 2014;171:4413-4424.

6 Yeung SY, Pucovský V, Moffatt JD, Saldanha L, Schwake M, Ohya S, Greenwood IA: Molecular expression and pharmacological identification of a role for Kv7 channels in murine vascular reactivity. Br J Pharmacol 2007;151: 758-770.

7 Chadha PS, Jepps TA, Carr G, Stott JB, Zhu HL, Cole WC, Greenwood IA: Contribution of kv7.4/kv7.5 heteromers to intrinsic and calcitonin gene-related peptide-induced cerebral reactivity. Arterioscler Thromb Vasc Biol 2014;34:887-893.

8 Brueggemann LI, Mackie AR, Cribbs LL, Freda J, Tripathi A, Majetschak M, Byron KL: Differential protein kinase C-dependent modulation of Kv7.4 and Kv7.5 subunits of vascular Kv7 channels. J Biol Chem 2014;289: 2099-2111.

9 Zhong XZ, Harhun MI, Olesen SP, Ohya S, Moffatt JD, Cole WC, Greenwood IA: Participation of KCNQ (Kv7) potassium channels in myogenic control of cerebral arterial diameter. J Physiol 2010;588:3277-3293.

10 Jepps TA, Chadha PS, Davis AJ, Harhun MI, Cockerill GW, Olesen SP, Hansen RS, Greenwood IA: Downregulation of Kv7.4 channel activity in primary and secondary hypertension. Circulation 2011;124:602-611.

11 Chadha PS, Zunke F, Zhu HL, Davis AJ, Jepps TA, Olesen SP, Cole WC, Moffatt JD, Greenwood IA: Reduced KCNQ4-encoded voltagedependent potassium channel activity underlies impaired $\beta$-adrenoceptor-mediated relaxation of renal arteries in hypertension. Hypertension 2012;59:877-884.

12 Khanamiri S, Soltysinska E, Jepps TA, Bentzen BH, Chadha PS, Schmitt N, Greenwood IA, Olesen SP: Contribution of Kv7 channels to basal coronary flow and active response to ischemia. Hypertension 2013;62:1090-1097.

13 Stott JB, Barrese V, Jepps TA, Leighton EV, Greenwood IA: Contribution of Kv7 channels to natriuretic peptide mediated vasodilation in normal and hypertensive rats. Hypertension 2015;65:676-682.

14 Stott JB, Povstyan OV, Carr G, Barrese V, Greenwood IA: G-protein $\beta \gamma$ subunits are positive regulators of Kv7.4 and native vascular Kv7 channel activity. Proc Natl Acad Sci USA 2015;112:6497-6502.

15 Mani BK, Robakowski C, Brueggemann LI, Cribbs LL, Tripathi A, Majetschak M, Byron KL: Kv7.5 potassium channel subunits are the primary targets for PKA-dependent enhancement of vascular smooth muscle Kv7 currents. Mol Pharmacol 2016;89:323-334.

16 Vassalle C, Simoncini T, Chedraui P, PérezLópez FR: Why sex matters: the biological mechanisms of cardiovascular disease. Gynecol Endocrinol 2012;28:746-751.

17 Gonzales RJ: Androgens and the cerebrovasculature: modulation of vascular function during normal and pathophysiological conditions. Pflugers Arch 2013;465:627-642.

18 Rossi P, Francès Y, Kingwell BA, Ahimastos AA: Gender differences in artery wall biomechanical properties throughout life. J Hypertens 2011;29:1023-1033.

19 Sandberg K, Ji H: Sex differences in primary hypertension. Biol Sex Differ 2012;3:7.

20 Doumas M, Papademetriou V, Faselis C, Kokkinos P: Gender differences in hypertension: myths and reality. Curr Hypertens Rep 2013; 15:321-330.

21 Dasinger JH, Alexander BT: Gender differences in developmental programming of cardiovascular diseases. Clin Sci (Lond) 2016; 130:337-348.

22 Lopes RA, Neves KB, Carneiro FS, Tostes RC: Testosterone and vascular function in aging. Front Physiol 2012;3:89.

23 Crump SM, Hu Z, Kant R, Levy DI, Goldstein SA, Abbott GW: Kcne4 deletion sex- and agespecifically impairs cardiac repolarization in mice. FASEB J 2016;30:360-369.

24 Livak KJ, Schmittgen TD: Analysis of relative gene expression data using real-time quantitative PCR and the 2(-Delta Delta C(T)) method. Methods 2001;25:402-408.

25 Mackie AR, Brueggemann LI, Henderson KK, Shiels AJ, Cribbs LL, Scrogin KE, Byron KL: Vascular KCNQ potassium channels as novel targets for the control of mesenteric artery constriction by vasopressin, based on studies in single cells, pressurized arteries, and in vivo measurements of mesenteric vascular resistance. J Pharmacol Exp Ther 2008;325:475483.

26 Mills TA, Greenwood SL, Devlin G, Shweikh Y, Robinson M, Cowley E, Hayward CE, Cottrell EC, Tropea T, Brereton MF, DalbyBrown W, Wareing M: Activation of KV7 channels stimulates vasodilatation of human placental chorionic plate arteries. Placenta 2015;36:638-644.

27 Yevenes GE, Moraga-Cid G, Guzmán L, Haeger S, Oliveira L, Olate J, Schmalzing G, Aguayo LG: Molecular determinants for $G$ protein betagamma modulation of ionotropic glycine receptors. J Biol Chem 2006;281: 39300-39307.

28 Moreno-Domínguez A, Cidad P, Miguel-Velado E, López-López JR, Pérez-García MT: De novo expression of Kv6.3 contributes to changes in vascular smooth muscle cell excitability in a hypertensive mice strain. J Physiol 2009;587:625-640.

29 Strutz-Seebohm N, Seebohm G, Fedorenko O, Baltaev R, Engel J, Knirsch M, Lang F: Functional coassembly of KCNQ4 with KCNE-beta-subunits in Xenopus oocytes. Cell Physiol Biochem 2006;18:57-66.

30 Roura-Ferrer M, Etxebarria A, Solé L, Oliveras A, Comes N, Villarroel A, Felipe A: Functional implications of KCNE subunit expression for the Kv7.5 (KCNQ5) channel. Cell Physiol Biochem 2009;24:325-334.

31 Roepke TK, King EC, Purtell K, Kanda VA, Lerner DL, Abbott GW: Genetic dissection reveals unexpected influence of $\beta$ subunits on KCNQ1 K+ channel polarized trafficking in vivo. FASEB J 2011;25:727-736.

32 Reckelhoff JF: Sex steroids, cardiovascular disease, and hypertension: unanswered questions and some speculations. Hypertension 2005; 45:170-174.

33 Ruige JB, Mahmoud AM, De Bacquer D, Kaufman JM: Endogenous testosterone and cardiovascular disease in healthy men: a meta-analysis. Heart 2011;97:870-875.

34 Fukai S, Akishita M, Yamada S, Ogawa S, Yamaguchi K, Kozaki K, Toba K, Ouchi Y: Plasma sex hormone levels and mortality in disabled older men and women. Geriatr Gerontol Int 2011;11:196-203.

35 Hyde Z, Norman PE, Flicker L, Hankey GJ, Almeida OP, McCaul KA, Chubb SA, Yeap $\mathrm{BB}$ : Low free testosterone predicts mortality from cardiovascular disease but not other causes: the Health in Men Study. J Clin Endocrinol Metab 2012;97:179-189.

36 Kundu P, Ciobotaru A, Foroughi S, Toro L, Stefani E, Eghbali M: Hormonal regulation of cardiac KCNE2 gene expression. Mol Cell Endocrinol 2008;292:50-62.

37 Roepke TK, Kontogeorgis A, Ovanez C, Xu X, Young JB, Purtell K, Goldstein PA, Christini DJ, Peters NS, Akar FG, Gutstein DE, Lerner DJ, Abbott GW: Targeted deletion of kcne2 impairs ventricular repolarization via disruption of I(K,slow1) and I(to,f). FASEB J 2008; 22:3648-3660.

38 Alzamora R, O'Mahony F, Bustos V, RapettiMauss R, Urbach V, Cid LP, Sepulveda FV, Harvey BJ: Sexual dimorphism and oestrogen regulation of KCNE3 expression modulates the functional properties of KCNQ1 K(+) channels. J Physiol 2011;589:5091-5107.

39 Abbott GW, Butler MH, Goldstein SA: Phosphorylation and protonation of neighboring MiRP2 sites: function and pathophysiology of MiRP2-Kv3.4 potassium channels in periodic paralysis. FASEB J 2006;20:293-301.

40 Zhou P, Fu L, Pan Z, Ma D, Zhang Y, Qu F, Guo L, Cao J, Gao Q, Han Y: Testosterone deprivation by castration impairs expression of voltage-dependent potassium channels in rat aorta. Eur J Pharmacol 2008;593:87-91.

41 Abbott GW: Biology of the KCNQ1 potassium channel. New J Sci DOI: 10.1155/2014/ 237431.

42 Abbott GW: The KCNE2 K(+) channel regulatory subunit: ubiquitous influence, complex pathobiology. Gene 2015;569:162-172.

43 Abbott GW: KCNE1 and KCNE3: the yin and yang of voltage-gated $\mathrm{K}(+)$ channel regulation. Gene 2016;576:1-13.

$44 \mathrm{Qu} \mathrm{J}$, Kryukova Y, Potapova IA, Doronin SV, Larsen M, Krishnamurthy G, Cohen IS, Robinson RB: MiRP1 modulates HCN2 channel expression and gating in cardiac myocytes. J Biol Chem 2004;279:43497-43502.

45 Liu W, Deng J, Wang G, Zhang C, Luo X, Yan D, Su Q, Liu J: KCNE2 modulates cardiac Ltype Ca channel. J Mol Cell Cardiol 2014;72: 208-218. 